\title{
A detached leaf assay to rapidly screen for resistance of maize to Bipolaris maydis, the causal agent of southern corn leaf blight
}

\author{
Elizabeth Aregbesola • Alejandro Ortega-Beltran • \\ Titilayo Falade • Gbolagade Jonathan • \\ Sarah Hearne • Ranajit Bandyopadhyay
}

Accepted: 10 October 2019/Published online: 26 November 2019

(C) The Author(s) 2019

\begin{abstract}
Southern corn leaf blight (SCLB), caused by the fungus Bipolaris maydis, is a disease that significantly affects maize productivity across the globe. A detached leaf assay (DLA) was developed to rapidly assess maize resistance to SCLB. Several experiments were conducted to: (i) identify a highly virulent B. maydis isolate; and to determine the most appropriate (ii) phytohormone to maintain viability of maize leaf tissue, (iii) leaf age for the assay, and (iv) inoculum concentration. Once optimized, the DLA was compared with screenhouse and field experiments. Use of DLA required a maximum of 28 days for resistance assessment, in contrast to screenhouse and field tests at a minimum of 33 and 72 days, respectively. DLA positively correlated with screenhouse $(\mathrm{r}=0.48, P=0.08)$ and field experiments $(\mathrm{r}=0.68, P=0.008)$. Assessments of diverse $B$. maydis strains and host genotypes
\end{abstract}

Electronic supplementary material The online version of this article (https://doi.org/10.1007/s10658-019-01870-4) contains supplementary material, which is available to authorized users.

E. Aregbesola $\cdot$ A. Ortega-Beltran $\cdot$ T. Falade $\cdot$ S. Hearne $\cdot$ R. Bandyopadhyay $(\bowtie)$

International Institute of Tropical Agriculture (IITA), PMB 5320, Oyo Road, Ibadan, Nigeria

e-mail: r.bandyopadhyay@cgiar.org

E. Aregbesola · G. Jonathan

University of Ibadan, PMB 5116, Ibadan, Nigeria

Present Address:

S. Hearne

International Maize and Wheat Improvement Center (CIMMYT), Texcoco, Mexico indicated that the DLA could be used to detect both highly virulent SCLB strains and highly resistant maize genotypes. Here we report that DLA is a rapid, reliable technique to screen maize resistance to SCLB. Use of this tool in maize breeding programs can speed up the process of identification of sources of resistance to multiple variants of SCLB.

Keywords Disease resistance $\cdot$ Screening methods . Maize breeding

\section{Introduction}

In sub-Saharan Africa (SSA), maize (Zea mays L.) provides well over $50 \%$ of the caloric intake of millions of people (van Ittersum et al. 2016). In addition, the crop is highly important for the livestock sector providing feed and forage. In Nigeria, circa 2 million tons of maize are required annually to satisfy the needs of the poultry sector alone (Heise et al. 2015). However, in tropical regions of SSA, maize production is frequently affected by southern corn leaf blight (SCLB), a foliar disease caused by the fungus Bipolaris maydis (Y. Nisik. and C. Miyake) Shoemaker (teleomorph: Cochliobolus heterostrophus Drechsler) (Kumar et al. 2016). The disease can be catastrophic such as during the infamous 1970-1971 epidemic in the US caused by Race T (Bhandari et al. 2017; Tatum 1971; Ullstrup 1972). The other races of B. maydis are Race $\mathrm{O}$ and Race $\mathrm{C}$. The former is a more successful saprophyte and thus prevails across the globe (Fisher et al. 1976). Race T 
ranks second in prevalence (Balint-Kurti et al. 2007; Blanco and Nelson 1972; Carson et al. 2004). Race C has only been reported in China (Carson et al. 2004; Wei et al. 1988). Losses associated with SCLB considerably impact livelihoods of farmers, food and feed sectors, and trade in countries where maize is a staple, including several SSA countries.

The fungus $B$. maydis was previously known as Helminthosporium maydis. In Nigeria, the SCLB disease has been reported since the 1950's (Cammack 1956). Craig (1971) found H. maydis to be widely distributed across Nigeria. In another study, Nelson et al. (1970) compared pathogenicity among $H$. maydis isolates from Africa, South America, Europe, and the USA, including three isolates native to Nigeria. In both studies, the B. maydis isolates native to Nigeria were described to have the characteristics of Race T. A more recent study revealed that $45 \%$ of tested farmers' seeds in Nigeria harbored the pathogen (Biemond et al. (2013).

There is large variability in susceptibilities of maize genotypes to SCLB although genotypes immune to the disease are not known (Bhandari et al. 2017; Mubeen et al. 2017). In order to assess susceptibilities to SCLB, maize genotypes are usually evaluated in screenhouse, greenhouse, and/or field experiments (Gao et al. 2005). A drawback is that those evaluations are both timeconsuming and resource-intensive with the ability to screen for SCLB susceptibility being restricted to B. maydis variants endemic to the area. Further, in some cases, the outcome of the evaluations is influenced by external factors preventing disease development and maize genotypes may be incorrectly assigned to a resistance category (Patial et al. 2017).

Management of SCLB requires an integrated approach composed of resistance, agronomic practices targeted towards reducing inoculum build-up, fungicide applications, among other practices (Lai et al. 2016; Shukla et al. 2012; Wang et al. 2015). Identifying resistant germplasm allows breeding programs to develop hybrids and synthetics with superior resistance to the disease and adapted to specific environments. This strategy was important for controlling the SCLB epidemic during the 1970s (Ullstrup 1972). Therefore, development of rapid, reliable assays to detect maize germplasm resistant to SCLB would be valuable for maize breeding programs across the globe.

Detached leaf assays (DLA) are rapid, low-cost laboratory-based techniques used to screen for resistance to both diseases caused by diverse pathogens and insect feeding (Green et al. 2000; Michel et al. 2010; Twizeyimana et al. 2007b). Viable leaf tissue is plated onto culture media and then inoculated with a pathogen or pest of interest. The required leaf material for each DLA is small (e.g., 5- $\mathrm{cm}^{2}$ pieces). Thus, DLA allows to rapidly screen large numbers of genotypes in a relatively small area, under controlled conditions, and planting space and resources are saved. Maize breeding programs aiming to develop SCLB resistant maize germplasm would benefit if a DLA is made available. Therefore, the objective of the current study was to develop a DLA to rapidly screen for maize resistance to B. maydis. To assess the efficacy of the assay, DLA results were compared with those from both screenhouse and field experiments.

\section{Materials and methods}

Isolation of Bipolaris maydis

Naturally infected maize plants of different varieties showing characteristic symptoms of SCLB were identified in research fields of the International Institute of Tropical Agriculture (IITA), Ibadan, Nigeria $\left(07^{\circ} 30^{\prime}\right.$ 20.7' N; 0354'08.4" E). Infected leaves were detached, placed inside labeled plastic bags, and immediately taken to the laboratory. Leaf lesions were excised using a sterile scalpel, surface-sterilized with $1 \% \mathrm{NaOCl}$ for $1 \mathrm{~min}$, and rinsed in four changes of sterile water. Surface-sterilized leaf fragments were gently tapped on sterile paper towel to remove excess water. Leaf fragments were then transferred into a moist chamber and incubated for $3 \mathrm{~d}\left(12 \mathrm{~h}\right.$ photoperiod, $\left.25^{\circ} \mathrm{C}\right)$. After incubation, sectors of mycelia were transferred to acidified potato dextrose agar (APDA, amended with $0.15 \%$ lactic acid). Lactic acid prevents bacterial growth when isolating fungi (Michailides et al. 1997). Isolates were then single-spored in APDA and incubated for $7 \mathrm{~d}(12 \mathrm{~h}$ photoperiod, $25^{\circ} \mathrm{C}$ ). Recovered single-spored isolates were saved in APDA slants and stored at $4{ }^{\circ} \mathrm{C}$ until used. In total, 15 SCLB isolates were saved.

Inoculum preparation

Inoculum was prepared by independently growing each of the 15 SCLB isolates on APDA for $14 \mathrm{~d}(12 \mathrm{~h}$ 
photoperiod, $25{ }^{\circ} \mathrm{C}$ ). After incubation, cultures were flooded with $15 \mathrm{ml}$ sterile $1 \%$ TWEEN®20 and spores were dislodged using a sterile spreader. The $1 \%$ TWEEN®20 solution allowed to emulsify the spores into suspension. Suspensions were filtered through two layers of sterile cheese cloth and adjusted to a concentration of $10^{5}$ spores $\mathrm{ml}^{-1}$ using a haemocytometer. Eighty grams of autoclaved, sterile sorghum were inoculated with $20 \mathrm{ml}$ spore suspension of each isolate and incubated for $10 \mathrm{~d}\left(12 \mathrm{~h}\right.$ photoperiod, $\left.25^{\circ} \mathrm{C}\right)$. Sorghum grains were soaked overnight prior to sterilization. Sorghum grains inoculated with sterile distilled water served as negative control.

\section{Virulence of B. maydis isolates}

Sam-09-3223, an open pollinated variety (OPV) of maize developed for use in Nigeria, was independently inoculated with sorghum grains colonized by each of the 15 B. maydis isolates to assess their virulence. Sam-093223, provided by the IITA Maize Breeding Unit, is known to be relatively resistant to SCLB. The virulence assessment was conducted by inoculating 3-week-old maize plants grown in a screenhouse (a netting-covered structure-instead of plastic or glass-that prevents pests to come in contact with the plants and also protects the plants from severe weather conditions). Four sorghum grains colonized by a $B$. maydis isolate were aseptically placed in maize whorls using sterile forceps. Forceps were disinfected between treatments with $70 \%$ ethanol to prevent cross contamination. Three plants were inoculated per isolate. Three plants inoculated with four sterilized, uninoculated sorghum grains served as the control. After inoculation, plants were covered for $24 \mathrm{~h}$ with clear plastic bags to maintain high humidity and promote disease development. Covering the plants during the $24 \mathrm{~h}$ also prevented the inoculum from being washed-off as a result of misting. Pots containing the plants were arranged in a completely randomized block design. The temperature in the screenhouse was in average $25{ }^{\circ} \mathrm{C}$ day and night. Relative humidity was maintained at $>95 \%$ by providing mist using a fogging machine (Reldair Fogging System, Reldairbv, Edisonstraat, The Netherlands). Plants received mist throughout the first night of inoculation and subsequently for $15 \mathrm{~min}$ in $30 \mathrm{~min}$ intervals during daylight (from 7:30 am to $6: 30 \mathrm{pm}$ ) until the onset of symptom appearance. After 2 weeks, plants were re-inoculated as above, regardless of the appearance of symptoms. Virulence assessment was rated on a 1 to 5 severity scale where: $1=$ no visible symptoms/chlorotic flecks; $2=$ up to $10 \%$ leaf area covered with small restricted lesions; $3=11$ to $25 \%$ leaf area covered with small restricted lesions; $4=$ 26 to $50 \%$ leaf area covered with large coalescing lesions; $5=>50 \%$ leaf area covered with large coalescing lesions. Disease severity was assessed every 3 days until 42 days after inoculation (dai). Thereafter, the sum of severity ratings was used to assess the virulence of each isolate. The experiment was repeated twice. Fungal cultures were made from diseased tissues to investigate the Koch postulates.

Optimization of the detached leaf assay (DLA)

DLA conditions were optimized by investigating influences of different phytohormones, leaf age, and inoculum concentration on disease development. To optimize the conditions for the DLA, the second-youngest fully unfolded healthy leaf of maize plants grown in the screenhouse were excised and collected in paper bags at 2 weeks (V5 stage) after planting, unless stated otherwise. After excision, leaves were sprayed with sterile water-to prevent leaf curling-and then immediately transferred to the laboratory, cut in $5-\mathrm{cm}^{2}$ sections with a sterile scalpel, disinfected in $1 \% \mathrm{NaOCl}$ for $1 \mathrm{~min}$, washed in four changes of sterile water, blotted dry, and plated on the surface of media in Petri dishes (9-cm-dia).

Assessment of phytohormones Seven phytohormones and sucrose were independently amended into $1 \%$ Technical Agar (Oxoid, Unipath Ltd., Hampshire, England). The phytohormones were gibberellic acid (GA; BDH Laboratory Supplies, Poole, England), kinetin (KIN; Fisher Scientific, Fair Lawn, NJ, USA), 6-benzylamino purine (BAP; Sigma-Aldrich, Steinheim, Germany), naphthalene acetic acid (NAA; Sigma-Aldrich), indole butyric acid (IBA; BDH Laboratory Supplies), benzimidazole (BEN; Sigma-Aldrich), and indole-3-acetic acid (IAA; SigmaAldrich). Sucrose was purchased from Fisher Scientific. Each compound was tested at 10 concentrations starting at $5 \mu \mathrm{g} \mathrm{ml}^{-1}$ and up to $50 \mu \mathrm{g} \mathrm{ml}^{-1}$, in $5 \mu \mathrm{g} \mathrm{ml}^{-1}$ increments. Media amendments were made aseptically after autoclaving $\left(121^{\circ} \mathrm{C}, 15 \mathrm{~min}, 15 \mathrm{psi}\right)$. Detached leaves of Sam-093223 were evaluated on each media in triplicate. Chlorosis levels were scored using a 1 -to- 9 scale, where $1=0$ to $5 \%$ chlorosis, and $9=>80 \%$ chlorosis (Twizeyimana et al. 2007a). Leaf sections placed on 1\% Technical Agar with no amendments served as negative controls. Chlorosis was 
measured 2 days after plating and every day until the 16th day. The experiment was repeated twice.

Assessment of leaf age Sections of leaves were obtained from Sam-09-3223 and 09A0009 plants at 2, 4 , and 6 weeks after planting (i.e., V5, V9, and V12 stages, respectively). Leaf sections were placed onto in $1 \%$ Technical Agar amended with $45 \mu \mathrm{g} \mathrm{ml}{ }^{-1}$ BAP, and incubated for $18 \mathrm{~d}(12 \mathrm{~h}$ photoperiod, $25^{\circ} \mathrm{C}$ ) in a complete randomized design. Leaf sections plated on $1 \%$ Technical Agar with no amendments served as negative control. Chlorosis was measured as above. Each treatment consisted of three replicates. The experiment was repeated twice.

Assessment of optimum spore concentration Five spore concentrations, $10^{2}, 10^{3}, 10^{4}, 10^{5}$, and $10^{6}$ spores $\mathrm{ml}^{-1}$, were tested on leaf sections of Sam-09-3223, 09A0009, and 09A3033. Spores of isolate SLB15 were obtained and adjusted as described above. Leaf sections placed on $1 \%$ Technical Agar amended with $45 \mu \mathrm{g} \mathrm{ml}^{-1}$ BAP were independently inoculated on the center by dropping $8 \mu \mathrm{l}$ of each spore suspension in the center of leaf sections using a pipettor. Leaf sections inoculated with $8 \mu \mathrm{l}$ sterile $1 \%$ TWEEN®20 served as negative controls. Plates were incubated for $10 \mathrm{~d}$ (12 h photoperiod, $25^{\circ} \mathrm{C}$ ). The experiment was arranged in a complete randomized design with three replicates per treatment. Two dai, before disease rating commenced, all fungal growth was aseptically removed using sterile cotton moistened with sterile distilled water. The removal of the fungal growth prevented secondary infection and subsequent rapid leaf death. Care was taken not to damage the leaf sections or to contaminate the tissue. Disease severity was assessed daily until 10 dai. Disease severity values were obtained by measuring the area of affected leaf sections and converting it to percentage leaf area affected as follows:

$\frac{\text { Width of leaf area affected }}{\text { Width of total leaf area }} \times \frac{\text { Length of leaf area affected }}{\text { Length of total leaf area }} \times 100=$ Percentage leaf area

The experiment was conducted twice.

Maize germplasm used in DLA, screenhouse, and field tests

Fourteen maize OPVs (Sam-09-3223, Sam-20103531, 9071, 09A0002, 09A0004, 09A0005, 09A0008, 09A0009, 09A0020, 09A3033, 09A3147, 09A3159, 10A3713, and 09A0096) provided by IITA Maize Breeding Unit were evaluated to assess susceptibilities to the most virulent B. maydis isolate, SLB15. Those OPVs are relatively commonly used by farmers in South West Nigeria and under natural conditions have been observed to possess variable levels of resistance to SCLB (unpublished results). Evaluations were conducted in DLA, screenhouse, and field experiments.

\section{DLA}

Leaf sections $\left(5-\mathrm{cm}^{2}\right)$ from 2-week-old maize plants of the 14 OPVs were plated on media containing $1 \%$ Technical Agar, $1.5 \mathrm{ml} \mathrm{l}^{-1}$ lactic acid, $12.5 \mathrm{mg} \mathrm{l}^{-1}$ benomyl, and $45 \mu \mathrm{g} \mathrm{ml}^{-1}$ BAP. Benomyl was added to prevent saprophytic fungi from growing. B. maydis is naturally resistant to benomyl (Gafur et al. 1998). Leaf sections were inoculated with a drop of $8 \mu$ of spore suspension $\left(10^{5}\right.$ spores $\left.\mathrm{ml}^{-1}\right)$ of $B$. maydis isolate SLB15. Plates were incubated for $14 \mathrm{~d}$ (12 h photoperiod, $25^{\circ} \mathrm{C}$ ) in a completely randomized block design with four replicates per treatment. Leaf sections inoculated with $8 \mu \mathrm{l}$ sterile $1 \%$ TWEEN®20 served as negative control. At two dai, fungal growth was aseptically removed as described above. Disease severity was assessed every day from 2 to 14 dai as percentage leaf area affected. The Area Under the Disease Progress Curve (AUDPC) was calculated as described in the data analysis section below. The experiment was conducted twice.

Resistance of maize genotypes to SCLB in the screenhouse

All 14 maize OPVs were grown in the screenhouse. Three-week-old plants were inoculated with sorghum grains colonized by B. maydis isolate SLB15 
as described above. Pots were arranged in a completely randomized block design with three replicates per cultivar. Screenhouse conditions were maintained as above. Disease ratings in percentage area affected were determined at four dai and thereafter every 3 days until 37 dai. Disease was estimated by calculating the AUDPC. The experiment was conducted twice.

Resistance of maize genotypes to SCLB in the field

The 14 maize OPVs were planted in an IITA-Ibadan research field in a balanced completely randomized design to evaluate their susceptibility to SCLB under natural conditions. Each treatment plot consisted of one row 3-m-long, randomly replicated three times. Each row had 13 hills separated by $25 \mathrm{~cm}$. Distance between rows was $75 \mathrm{~cm}$. Plots were separated at the end by 1-m-wide unplanted alleys. Maize seeds were sown at three seeds per hill and 3 weeks after planting thinned to one plant per hill. The border rows were planted with maize hybrid Oba-Super 1. Fertilizer, herbicide, and insecticide treatments were applied according to recommended doses for South West Nigeria. Fields had overhead irrigation, which promoted favourable conditions for disease development. No fungicides were applied to prevent experimental interference. Disease ratings were done at 28 days after planting (dap) and until 72 dap every 3 days. Disease severity was calculated as percentage area affected of two randomly selected and tagged leaves per plant.

Data analysis

All data was examined with SAS version 9.2 (SAS Institute Inc., Cary, NC). Before analysis all data obtained from all experiments were tested for homogeneity of variance. Heterogeneity was not detected. Data from experiments to determine optimum inoculum concentration were subjected to analysis of variance (ANOVA) using the GLM procedure. Data of experiments to determine appropriate leaf age and plant hormone were analyzed by repeated measures ANOVA using the GLM procedure. Fisher's protected least significant difference (LSD) test $(\alpha=0.05)$ was used to separate mean values.

Mean disease ratings for DLA, screenhouse, and field experiments were calculated and used to compute the AUDPC (Campbell and Madden 1990). AUDPC was calculated as follows:

$A U D P C=\sum_{i=1}^{n-1}\left[\left(D_{i}+D_{i+1}\right)\right] / 2\left[t_{i+1}-t_{i}\right]$

Where $n$ is the total number of observations, $t_{i}$ is time (days) at the ith observation days and $D_{i}$ is disease severity (percentage infected leaf area at the ith D observation).

AUDPC data were analyzed after square-root transformation, to comply with ANOVA assumptions. AUDPC data were first analyzed separately by type of experiment (e.g., DLA) and then all three experiments were analyzed together (i.e., DLA, screenhouse, and field). Fisher's protected LSD test $(\alpha=0.05)$ was used to separate means of square-root transformed AUDPC values. For each OPV, means of transformed AUDPC values from DLA, screenhouse, and field experiments were compared by Pearson's correlation using the CORR procedure $(\alpha=0.05)$.

\section{Results}

B. maydis isolation and assessment of isolates' virulence

Fifteen $B$. maydis isolates recovered from naturally infected maize plants grown in IITA research fields were characterized. Morphological characteristics of the recovered isolates are presented in Fig. 1. Conidia of all isolates were olivaceous-brown, curved, and spindled shaped ( size $=17-20 \mu \mathrm{m} \times 70$ $145 \mu \mathrm{m})$. The conidia contained 5-11 septa and had bipolar germination. Isolate SLB15 was the most virulent when evaluated on OPV Sam-093223 (Table 1). Therefore, SLB15 was selected to both optimize the DLA and to assess resistance of 14 maize OPVs to B. maydis using DLA, screenhouse, and field experiments.

\section{Optimization of DLA}

There was no contamination in any of the media despite the addition of the amendments after autoclaving. Chlorosis responses significantly $(P<0.0001)$ varied depending on the phytohormone and time of incubation (Table 2). Leaf sections incubated on media containing BAP at $45 \mathrm{\mu gml}^{-1}$ had less chlorosis than those 
Fig. 1 Morphological

characteristics of the recovered

Bipolaris maydis isolates. a

Conidia of B. maydis. b

Germinating conidium at both ends, characteristic of B. maydis. c Photomicrograph of infected maize leaf with $B$. maydis conidia: (1) conidium, (2) conidiophore bearing the conidium at the tip (3) conidiophore having emerged from the stomata

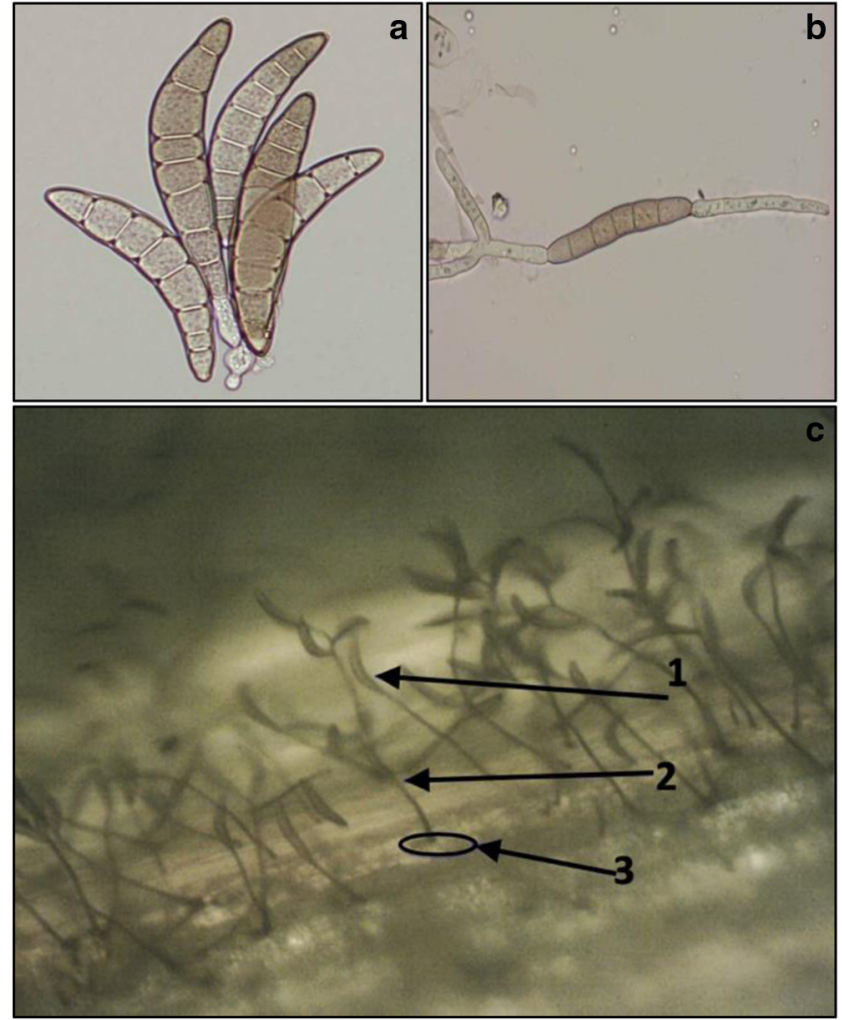

Table 1 Mean disease severity values caused by 15 isolates of Bipolaris maydis, the causal agent of southern corn leaf blight, on maize open pollinated variety Sam-09-3223

\begin{tabular}{lll}
\hline Isolate & \multicolumn{2}{l}{ Disease rating } \\
\cline { 2 - 3 } & Mean $^{\mathrm{a}}$ & Std Dev \\
\hline SLB01 & $2.39 \mathrm{fgh}$ & 1.23 \\
SLB02 & $2.91 \mathrm{bcde}$ & 1.38 \\
SLB03 & $2.64 \mathrm{defg}$ & 1.17 \\
SLB04 & $2.14 \mathrm{~h}$ & 1.21 \\
SLB05 & $3.13 \mathrm{abc}$ & 1.06 \\
SLB06 & 2.23 gh & 1.04 \\
SLB07 & $2.45 \mathrm{efgh}$ & 1.44 \\
SLB08 & $3.30 \mathrm{ab}$ & 1.26 \\
SLB09 & $3.11 \mathrm{abcd}$ & 1.27 \\
SLB10 & $3.09 \mathrm{abcd}$ & 1.65 \\
SLB11 & $3.09 \mathrm{abcd}$ & 1.30 \\
SLB12 & $3.07 \mathrm{abcd}$ & 1.50 \\
SLB13 & $3.05 \mathrm{abcd}$ & 1.20 \\
SLB14 & $2.82 \mathrm{cdef}$ & 1.39 \\
SLB15 & $3.52 \mathrm{a}$ & 1.57 \\
Non-inoculated control & $1.00 \mathrm{i}$ & 0.00 \\
\hline
\end{tabular}

${ }^{a}$ Means with the same letter are not significantly different according to Fisher's least significant difference test $(\alpha=0.05)$ incubated in media containing any other compound, regardless of their concentration (Fig. 2). BEN at $5 \mu \mathrm{g} \mathrm{ml}^{-1}$ was the least effective phytohormone for maintaining green leaf area. Media amended with BAP at $45 \mu \mathrm{g} \mathrm{ml}^{-1}$ was used in other tests to continue optimizing the DLA and in the optimized DLA.

Within the investigation period, the extent of changes in leaf chlorosis differed significantly by leaf age and genotype (Table 3). OPV 09A0009 had less chlorosis compared to Sam-09-3223 (Fig. 3). For both OPVs, younger leaves had less chlorosis (Fig. 3). Therefore, 2-week-old leaves were selected.

The lowest and the highest spore concentrations were discarded because the former, $10^{2}$ spores $\mathrm{ml}^{-1}$, yielded no visible disease symptoms, and the latter, $10^{6}$ spores $\mathrm{ml}^{-1}$, led to rapid tissue death, over $88 \%$ of the examined area within three dai. In both genotypes, disease severity was higher $(P<0.05)$ in leaves inoculated with suspensions containing $10^{5}$ spores $\mathrm{ml}^{-1}$ (Fig. 4) than in leaves inoculated with lesser fungal concentrations and therefore that concentration was selected for further evaluations. The day $\times$ treatment interaction was significant $(P<0.0001)$ for disease severity at all points of assessment (Table 4). 
Table 2 Mean square and $\mathrm{F}$ values for the effect of different phytohormones on chlorosis of detached maize leaves

\begin{tabular}{|c|c|c|c|c|c|}
\hline Source & $\mathrm{DF}$ & Type III sum of squares & Mean square & $\mathrm{F}$ value & $P$ value \\
\hline Day $^{\mathrm{a}}$ & 8 & $30,443.7$ & 3805.5 & 2068.9 & $<0.0001$ \\
\hline Hor $^{\mathrm{b}}$ & 80 & 3318.4 & 41.5 & 22.5 & $<0.0001$ \\
\hline Day $\times$ Hor $^{\mathrm{c}}$ & 640 & 1611.6 & 2.5 & 1.4 & $<0.0001$ \\
\hline
\end{tabular}

${ }^{\mathrm{a}}$ Day refers to the day of assessment after plating on each hormone treatment, ${ }^{\mathrm{b}}$ Hormone, ${ }^{\mathrm{c}}$ Interaction between assessment day and each of the hormones

\section{DLA evaluation}

DLA was conducted using the selected phytohormone, leaf age, and spore concentration mentioned above. All leaves showed symptoms — which appeared as early as two dai - except for those used in the control treatment. However, disease severity significantly $(P<0.05)$ varied among the examined OPVs (Table 5). Sam-20103531 had the lowest AUDPC value (49) and 10A3713 had the highest value (393) (Table 5).

\section{Screenhouse evaluation}

Disease severity significantly $(P<0.05)$ varied among the 14 maize OPVs (Table 5). In some OPVs, symptoms were expressed as early as one dai while in others disease progression was slow. OPVs 09A3033 and 9071 had the lowest and highest AUDPC values at 569 and 1642, respectively (Table 5).

\section{Field evaluation}

Disease symptoms started in most maize OPVs before disease ratings commenced at 28 dap. At the end of the evaluations, Sam-2010-3531 and 09A3159 exhibited no SCLB symptoms (Table 5). The mean AUDPC value for the field assessment was 957. OPVs 9071 and 10A3713 had AUDPC values of over 3000. Some of the OPVs were also affected by other foliar fungal diseases such as northern corn leaf blight by Exserohilum turcicum and/or Curvularia leaf spot (data not shown).

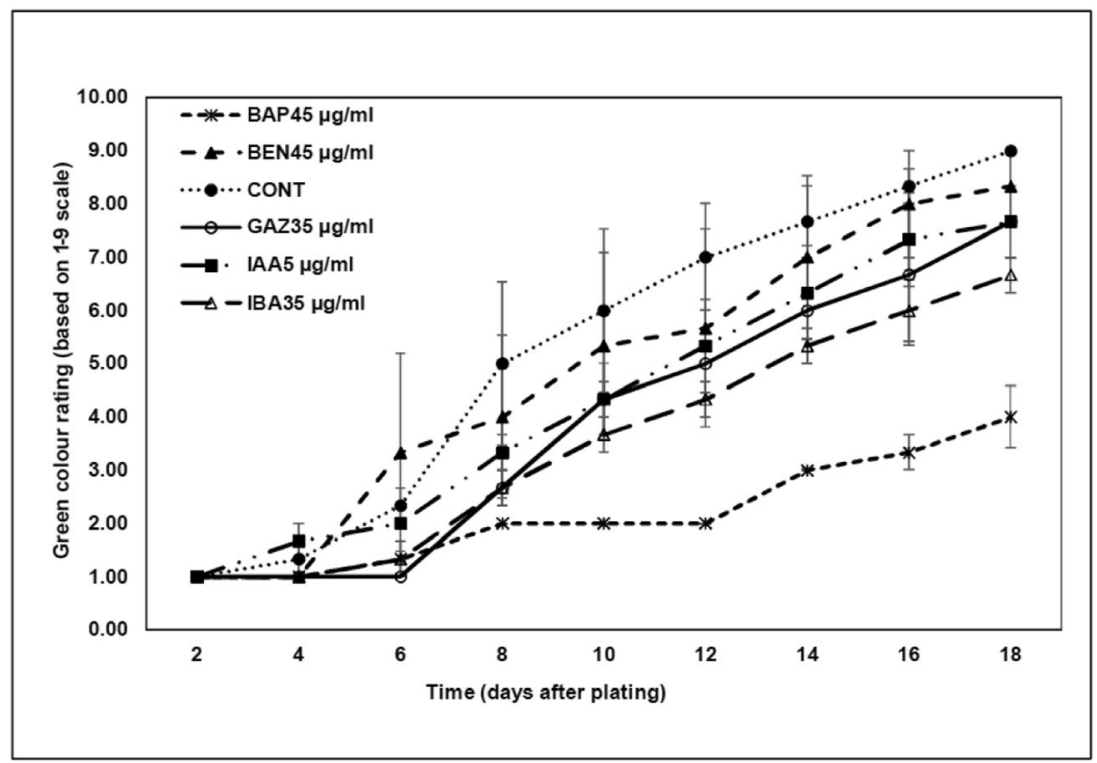

Fig. 2 Influence of phytohormones on chlorosis of detached maize leaves. Results of five of the seven tested phytohormones are presented. For each phytohormone, 10 concentrations were tested. Only that concentration yielding low chlorosis is reported in this figure. Vertical bars represent standard errors of mean percent chlorosis. Leaves were rated using a 1-to-9 scale developed by Twizeyimana et al. (2007b), where $1=$ no chlorosis and 9 $=>80 \%$ leaf chlorosis. $\mathrm{BAP}=6$-benzylamino purine, $\mathrm{BEN}=$ Benzimidazole, $\mathrm{CONT}=$ Control, $\mathrm{GAZ}=$ Gibberellic acid, $\mathrm{IAA}=$ Indole-3-acetic acid, and IBA = Indol-3-ylbutyric acid 
Table 3 Mean square and $\mathrm{F}$ values for the effect of leaf age on chlorosis of detached maize leaves

\begin{tabular}{|c|c|c|c|c|c|}
\hline & $\mathrm{DF}$ & Type III SS & Mean square & $\mathrm{F}$ value & $P$ value \\
\hline Day & 8 & 802.1 & 100.3 & 67.0 & $<.0001$ \\
\hline $\mathrm{LA}^{\mathrm{a}}$ & 2 & 210.8 & 105.4 & 70.4 & $<.0001$ \\
\hline Genotype & 1 & 277.4 & 277.4 & 185.4 & $<.0001$ \\
\hline LA $\times$ Genotype $^{\mathrm{b}}$ & 2 & 39.0 & 19.5 & 13.1 & $<.0001$ \\
\hline Day $\times \mathrm{LA}^{\mathrm{c}}$ & 16 & 62.2 & 3.9 & 2.6 & 0.0015 \\
\hline
\end{tabular}

${ }^{\mathrm{a}}$ Leaf age, ${ }^{\mathrm{b}}$ Interaction between each leaf age and genotype, ${ }^{\mathrm{c}}$ Interaction between assessment day and each leaf age

Comparison of DLA, screenhouse, and field evaluations

There was a positive, significant correlation between DLA and field evaluations $(\mathrm{r}=0.68, n=14, P=$ 0.008 ) and between screenhouse and field evaluations ( $\mathrm{r}=0.68, n=14, P=0.008)$. On the other hand, there was a positive but non-significant correlation between DLA and screenhouse evaluations $(\mathrm{r}=0.48$, $n=14, P=0.08$; Table 6).

\section{Discussion}

Detached leaf assays are useful tools to screen crop cultivars to diverse diseases (Rajkumar et al. 2005;
Boydom and Dawit 2013; Arraiano et al. 2001; Felsenstein et al. 1998; Zandjanakou-Tachin et al. 2013; Weihmann et al. 2016; Degani and Cernica 2014); Twizeyimana et al. 2007a; Moročko et al. 2006) and insect pests (Maharijaya et al. 2011; Sharma et al. 2005). We report a rapid, reliable DLA to screen maize genotypes for resistance to SCLB, a disease caused by the fungus $B$. maydis. The method builds upon preliminary work in our laboratory, in which a DLA to screen for resistance to soybean rust was developed (Twizeyimana et al. 2007a). In contrast with other DLA methods developed for maize (Weihmann et al. 2016; Degani and Cernica 2014), our method allows evaluating a maize disease for long periods. DLA was compared with screenhouse and field screening

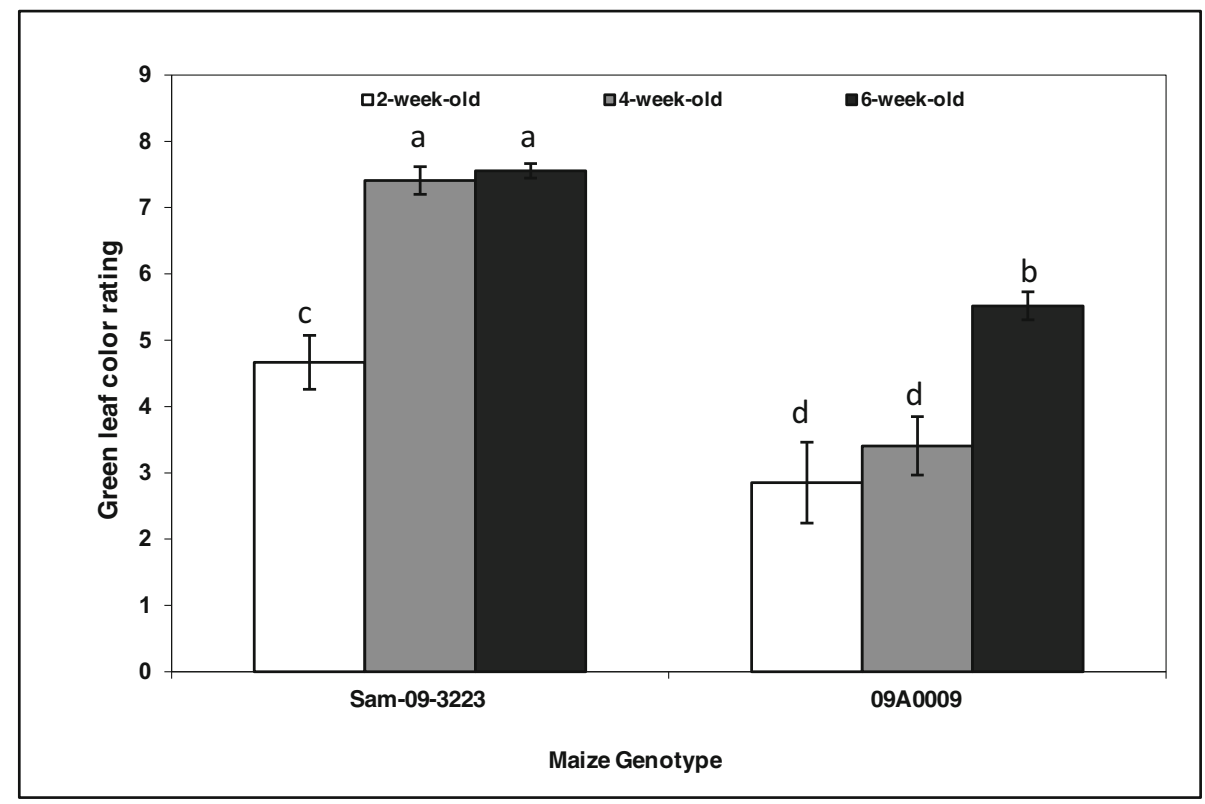

Fig. 3 Influence of leaf age on chlorosis. Leaf sections of two maize OPVs were evaluated for 18 days (the mean is reflected in the bar chart). Leaf sections were plated on 1\% Technical Agar amended with $45 \mathrm{\mu g} \mathrm{ml}^{-1}$ BAP. Leaves were rated using a 1-to-9 scale developed by Twizeyimana et al. (2007b), where $1=$ no chlorosis and $9=>80 \%$ leaf chlorosis. Means significantly different are marked by different letters (LSD, $\alpha=0.05$ ) 


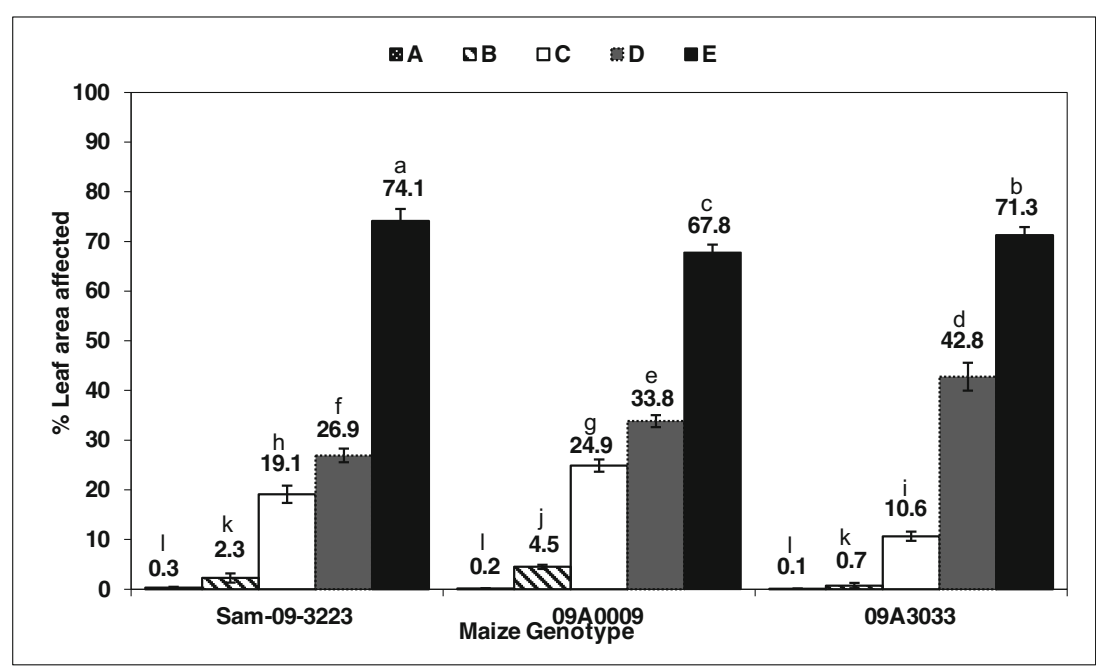

Fig. 4 Influence of spore concentration on disease severity. Five spore concentrations of a Bipolaris maydis isolate were evaluated in leaf sections of three maize OPVs (the mean is reflected in the bar chart). Evaluations were conducted in sections of detached leaves plated on $1 \%$ Technical Agar amended with $45 \mu \mathrm{g} \mathrm{ml}^{-1}$

methods. Field screening is traditionally used to assess maize susceptibilities to SCLB (Bhandari et al. 2017; Singh et al. 2014; Srivastava et al. 2017). However, field screening is both resource-intensive and time-consuming. It can take over 70 days to complete field evaluations (Bhandari et al. 2017). The DLA developed and validated in the current study allows for faster evaluation of maize germplasm at a fraction of the cost of either the screenhouse or field evaluations. The DLA allows evaluating large numbers of genotypes, and can be useful to evaluate resistance to other foliar pathogens, after determining appropriate inoculum concentrations. Comparison of the responses of 14 maize OPVs under DLA, screenhouse, and field screens indicates that reliable resistance assessment can be confirmed as soon as two dai, equivalent to 16 dap, in the DLA, whereas screenhouse and field evaluations required a minimum of 33 and 72 dap, respectively.
BAP, for 10 days. Bars with the same letter represent means that are statistically similar to one another (LSD, $\alpha=0.05$ ). $\mathbf{A}=10^{2}$ spores $\mathrm{ml}^{-1}, \mathbf{B}=10^{3}$ spores $\mathrm{ml}^{-1}, \mathbf{C}=10^{4}$ spores $\mathrm{ml}^{-1}, \mathbf{E}=10^{5}$ spores $\mathrm{ml}^{-1}$, and $\mathbf{E}=10^{6}$ spores $\mathrm{ml}^{-1}$

In addition to providing a rapid assessment, using DLA has significantly less risks of obtaining ambiguous results caused by co-infection of diverse pathogens, insect damage, or abiotic variables that occur in the field and may occur in screenhouse conditions. Furthermore, with appropriate pathogen quarantine protocols, a large number of both maize germplasm and $B$. maydis strains can be evaluated simultaneously. Moreover, DLA can overcome limitations associated with both field and screenhouse tests such as space, frequency, cost, and experiment duration. In the field, variation caused by environmental factors may not always allow disease to develop, especially if the evaluation relies on natural infection. In the current study, maize OPVs Sam-20103531 and 09A3159 exhibited no SCLB disease symptoms under field conditions. Whether these OPVs possess resistance to the $B$. maydis genotypes that were present in the field is unknown. We did not characterize B. maydis communities interacting with the maize in

Table 4 Mean square and F values for the effect of spore concentration on disease development on detached maize leaves

\begin{tabular}{llllll}
\hline Source & DF & Type III sum of squares & Mean Square & F value & P value \\
\hline Genotype & 2 & 3.2 & 1.6 & 2.5 & 0.09 \\
SC $^{\text {a }}$ & 4 & 4278.5 & 1069.6 & 1647.9 & $<0.0001$ \\
Day & 8 & 1555.6 & 194.5 & 299.6 & $<0.0001$ \\
SC $\times$ Day $^{\text {b }}$ & 32 & 1450.0 & 45.3 & 69.8 & $<0.0001$ \\
\hline
\end{tabular}

${ }^{\mathrm{a}}$ Spore concentration, ${ }^{\mathrm{b}}$ Interaction between assessment day and each spore concentration 
Table 5 Mean area under disease progress curve (AUDPC) caused by a Bipolaris maydis isolate on 14 maize open pollinated varieties (OPVs) under three methods of evaluation

\begin{tabular}{|c|c|c|c|c|}
\hline \multirow[t]{2}{*}{ Maize OPV } & \multicolumn{4}{|c|}{ Method of evaluation $^{\mathrm{a}}$} \\
\hline & DLA $^{b}$ & Screenhouse & Field & Combined \\
\hline 09A3033 & $170 \mathrm{de}$ & $584 \mathrm{~g}$ & 1184 cdef & $538 \mathrm{fg}$ \\
\hline Sam-2010-3531 & $56 \mathrm{f}$ & $647 \mathrm{fg}$ & $0 \mathrm{f}$ & $281 \mathrm{~h}$ \\
\hline 09A3147 & $115 \mathrm{ef}$ & 816 efg & 1647 bcde & 702 def \\
\hline 09A3159 & 109 ef & 940 def & $0 \mathrm{f}$ & $419 \mathrm{gh}$ \\
\hline Sam-09-3223 & $311 \mathrm{abc}$ & 905 efg & $1229 \mathrm{cdef}$ & 732 def \\
\hline 9071 & $253 \mathrm{bcd}$ & $1418 \mathrm{ab}$ & $3034 \mathrm{a}$ & $1275 \mathrm{ab}$ \\
\hline 10A3713 & $389 \mathrm{a}$ & $1525 \mathrm{a}$ & 3033 a & $1372 \mathrm{a}$ \\
\hline 09A0096 & $305 a b c$ & 844 efg & 1654 bcde & 790 de \\
\hline 09A0002 & $336 \mathrm{ab}$ & 1153 bcde & $2666 \mathrm{ab}$ & $1129 \mathrm{bc}$ \\
\hline 09A0004 & $153 \mathrm{def}$ & $1337 \mathrm{abc}$ & $2469 a b c$ & $1090 \mathrm{bc}$ \\
\hline 09A0005 & $182 \mathrm{de}$ & 1124 bcde & 1911 abcde & $905 \mathrm{~cd}$ \\
\hline 09A0008 & 208 cde & $1255 \mathrm{abcd}$ & 960 def & 777 def \\
\hline 09A0009 & $129 \mathrm{ef}$ & 1089 bcde & 665 ef & 620 def \\
\hline 09A0020 & $210 \mathrm{cde}$ & 1039 cde & $2080 \mathrm{abcd}$ & $915 \mathrm{~cd}$ \\
\hline Mean & 208.9 & 1048.2 & 1609.4 & 824.7 \\
\hline$P$ & $<0.0001$ & 0.0002 & $<0.0001$ & $<0.0001$ \\
\hline $\mathrm{SE}$ & 38.2 & 22.8 & 455.1 & 78.8 \\
\hline $\mathrm{CV}(\%)$ & 29.3 & 14.2 & 27.1 & 21.1 \\
\hline
\end{tabular}

${ }^{\mathrm{a}}$ The statistical analysis was conducted with square-root transformed means. In the table, values of untransformed means are presented. Means with the same letter are not significantly different according to Fisher's least significant difference test $(\alpha=0.05)$, ${ }^{b}$ Detached leaf assay

those fields. Nevertheless, Sam-2010-3531 and 09A3159 consistently had AUDPC values well below the average, regardless of the screening method used (Table 4). This suggests that these genotypes possess superior resistance to SCLB and may be valuable to include in breeding programs aiming to develop SCLB resistant hybrid materials.

A critical aspect of DLA is to ensure that the examined leaf tissues remain viable, with little to no chlorosis. Absence of, or reduced chlorosis allows to properly

Table 6 Pearson correlation coefficients of area under disease progress curve (AUDPC) values by a Bipolaris maydis isolate on 14 maize open pollinated varieties on detached leaf assay (DLA), screenhouse, and field tests ${ }^{\mathrm{a}}$

\begin{tabular}{llll}
\hline & DLA & Field & Screenhouse \\
\hline DLA & 1.00 & $0.68^{*}$ & $0.48^{* *}$ \\
Field & & 1.00 & $0.68^{*}$ \\
Screenhouse & & & 1.00
\end{tabular}

${ }^{\text {a }}$ Values with an asterisk are significantly correlated $(\alpha=0.05)$ assess disease severity. Multiple phytohormones are known to prevent chlorosis in different plant species (Twizeyimana et al. 2007b; Loladze 2006; Asnaghi et al. 2001; Costa et al. 2005; Siddiqui et al. 2011). In the current study, BAP prevented maize chlorosis in a more efficient manner. Its use resulted in significantly less chlorosis levels compared to all other evaluated compounds (Fig. 2). BAP is considered an antisenescence hormone. BAP influences maintenance of chloroplast structure, thus delaying the senescence of the leaf (Zavaleta-Mancera et al. 2007). It has been reported that there is a greater retention of both chlorophyll levels and proteins in detached leaves of cocklebur plants after treatment with cytokinin, the class to which BAP belongs (Richmond and Lang 1957). However, in other DLA studies, it was found that the phytohormones KIN or BEN, or a combination of both, effectively reduced senescence of wheat when evaluating diverse diseases (Boydom and Dawit 2013; Felsenstein et al. 1998; Arraiano et al. 2001; Loladze 2006). Thus, development of DLA for a specific crop demands 
investigating both the most appropriate phytohormone and the proper concentration.

Since it is well-known that leaf age greatly influences pathogen infection (Chen et al. 1991; Emge et al. 1975) our DLA also was optimized for the most appropriate leaf age to use. It was found that younger leaves (2week-old) were more suitable for the assay. However, several foliar fungal diseases have a greater impact during vegetative stages. On the other hand, development of DLA using leaves from maize at advanced stages may not allow to conduct the DLA in a proper manner since viability is lost rapidly (unpublished results). In addition, other DLA developed for maize report reliable results when using leaves from 2- to 3week-old plants (Weihmann et al. 2016; Degani and Cernica 2014). In the current study, results of DLA using young leaves were correlated with results found when testing for resistance in older plants (Table 6). Thus, use of young leaves on DLA is a reliable predictor of susceptibility to SCLB. Moreover, use of DLA has the advantage of controlling the environmental conditions, and prevent biotic stresses caused by other microorganisms, and may be a more reliable method to screen for SCLB resistance than field experiments and screenhouse methods.

In the current study, variation in disease resistance was detected among the examined maize germplasm. The three screening methods identified Sam-2010-3531 and 09A3159 as OPVs with superior resistance to SCLB. It has been questioned whether resistance is controlled by one $(R h m)$ or more genes (Chang and Peterson 1995; Gao et al. 2005; Smith and Hooker 1973; Thompson and Bergquist 1983). Popular views remain that $\mathrm{Rhm}$ is the sole determinant for maize resistance to SCLB. However, genotypic differences among the OPVs were not investigated. In future studies, genetic variability between the examined OPVs should be conducted to determine the molecular basis of the resistance. Additionally, a comprehensive study examining the genetic diversity among B. maydis strains interacting with maize in Nigeria and West Africa would improve the understanding of pathogen diversity within the region.

Maize is the staple of millions of people across SSA. It is necessary to develop rapid methods to detect resistance to pathogens that significantly decrease maize productivity, such as B. maydis. The DLA that was developed, optimized, and validated during the course of our studies can be used to rapidly detect maize genotypes with superior resistance to SCLB. The DLA is an effective and reliable alternative tool for maize breeding programs. Future research efforts should consider increasing the number of maize genotypes screened for resistance to SCLB. In addition, the DLA should be adapted to screen for resistance to other major foliar pathogens of maize, as well as co-infection by several pathogens.

Acknowledgements This project was supported by CGIAR Research Program on MAIZE and the Bill and Melinda Gates Foundation (OPP45783.01; DTMA II: Drought Tolerant Maize for Africa - Phase II project). The authors are thankful to staff of IITA's Pathology and Maize Breeding Units for their support.

\section{Compliance with ethical standards}

Ethical statement All authors consent to the submission of this manuscript. The manuscript has been prepared following principles of ethical and professional conduct. The research did not involve human participants and did not involve animal subjects therefore neither submission of human consent nor statement on welfare of animals is applicable.

Conflict of interest The authors declare that they have no conflict of interest.

Open Access This article is distributed under the terms of the Creative Commons Attribution 4.0 International License (http:// creativecommons.org/licenses/by/4.0/), which permits unrestricted use, distribution, and reproduction in any medium, provided you give appropriate credit to the original author(s) and the source, provide a link to the Creative Commons license, and indicate if changes were made.

\section{References}

Arraiano, L. S., Brading, P. A., \& Brown, J. K. M. (2001). A detached seedling leaf technique to study resistance to Mycosphaerella graminicola (anamorph Septoria tritici) in wheat. Plant Pathology, 50, 339-346.

Asnaghi, C., D’Hont, A., Glaszmann, J. C., \& Rott, P. (2001). Resistance of sugarcane cultivar R 570 to Puccinia melanocephala isolates from different geographic locations. Plant Disease, 85, 282-286.

Balint-Kurti, P. J., Zwonitzer, J. C., Wisser, R. J., Carson, M., Oropeza-Rosas, M. A., Holland, J. B., \& Szalma, S. J. (2007). Precise mapping of quantitative trait loci for resistance to southern leaf blight, caused by Cochliobolus heterostrophus race $\mathrm{O}$, and flowering time using advanced intercross maize lines. Genetics, 176, 645-657.

Bhandari, R. R., Aryal, L., Sharma, S., Acharya, M., Pokhrel, A., Apar, G. C., Kaphle, S., Sahadev, K. C., Shahi, B., Bhattarai, K., Chhetri, A., \& Panthi, S. (2017). Screening of maize genotypes against southern leaf blight (Bipolaris maydis) 
during summer season in Nepal. World Journal of Agricultural Research, 5, 31-41.

Biemond, P. C., Oguntade, O., Stomph, T. J., Kumar, P. L., Termorshuizen, A. J., \& Struik, P. C. (2013). Health of farmer-saved maize seed in north-East Nigeria. European Journal of Plant Pathology, 137, 563-572.

Blanco, M. H., \& Nelson, R. R. (1972). Relative survival of populations of race $\mathrm{O}$ and race $\mathrm{T}$ of Helminthosporium maydis on a corn hybrid in normal cytoplasm. Plant Disease Report, 56, 889-891.

Boydom, A., \& Dawit, W. (2013). Evaluation of detached leaf assay for assessing leaf rust (Puccinia triticina Eriks.) resistance in wheat. Journal of Plant Pathology and Microbiology, 4, 176.

Cammack, R. H. (1956). Notes on the more important fungi affecting maize in Nigeria. West African Maize Research Unit Memorandum, No. 6.

Campbell, C. L., \& Madden, L. V. (1990). Introduction to plant disease epidemiology. John Wiley and Sons, USA.

Carson, M. L., Stuber, C. W., \& Senior, M. L. (2004). Identification and mapping of quantitative trait loci conditioning resistance to southern leaf blight of maize caused by Cochliobolus heterostrophus race O. Phytopathology, 94, 862-867.

Chang, R.-Y., \& Peterson, P. A. (1995). Genetic control of resistance to Bipolaris maydis: One gene or two genes. Journal of Heredity, 86, 94-97.

Chen, J. M., Black, T. A., \& Adams, R. S. (1991). Evaluation of hemispherical photography for determining plant area index and geometry of a forest stand. Agricultural and Forest Meteorology, 56, 129-143.

Costa, M. L., Civello, P. M., Chaves, A. R., \& Martinez, G. A. (2005). Effect of ethephon and 6-benzylaminopurine on chlorophyll degrading enzymes and a peroxidase-linked chlorophyll bleaching during post-harvest senescence of broccoli (Brassica oleracea L.) at $20^{\circ} \mathrm{C}$. Postharvest Biology and Technology, 35, 191-199.

Craig, J. (1971). Occurrence of Helminthosporium maydis Race T in West Africa. Plant Disease Reporter, 55, 672-673.

Degani, O., \& Cernica, G. (2014). Diagnosis and control of Harpophora maydis, the cause of late wilt in maize. Advances in Microbiology, 4, 94-105.

Emge, R. G., Kingsolver, C. H., \& Johnson, D. R. (1975). Growth of the sporulating zone of Puccinia striiformis and its relationship to stripe rust epiphytology. Phytopathology, 65, 679-681.

Felsenstein, F. G., Park, R. F., \& Zeller, F. J. (1998). The use of detached seedling leaves of Triticum aestivum to study pathogenecity in Puccinia recondita f. sp. tritici. Journal of Phytopathology, 146, 115-121.

Fisher, D. E., Hooker, A. L., Lim, S. M., \& Smith, D. R. (1976). Leaf infection and yield loss caused by four Helminthosporium leaf diseases of corn. Phytopathology, 66, 942-944.

Gafur, A., Tanaka, C., Shimizu, K., Ouchi, S., \& Tsuda, M. (1998). Molecular analysis and characterization of the Cochliobolus heterostrophus beta-tubulin gene and its possible role in conferring resistance to benomyl. Journal of General and Applied Microbiology, 44, 217-223.
Gao, Z. S., Cai, H. W., \& Liang, G. H. (2005). Field assay of seedling and adult-plant resistance to southern leaf blight in maize. Plant Breeding, 124, 356-361.

Green, K. R., Abang, M. M., \& Iloba, C. (2000). A rapid bioassay for screening yam germplasm for response to anthracnose. Tropical Science, 40, 132-138.

Heise, H., Crisan, A., \& Theuvsen, L. (2015). The poultry market in Nigeria: Market structures and potential for investment in the market. International Food and Agribusiness Management Review, 18, 197-222.

Kumar, B., Hooda, K. S., Gogoi, R., Kumar, V., Kumar, S., Abhishek, A., Bhati, P., Sekhar, J. C., Yathish, K. R., Singh, V., Das, A., Mukri, G., Varghese, E., Kaur, H., Malik, V., \& Yadav, O. P. (2016). Inheritance study and stable sources of Maydis leaf blight (Cochliobolus heterostrophus) resistance in tropical maize germplasm. Cereal Research Communications, 44, 1-11.

Lai, Y. -R., Lin, P. -Y., Chen, C. -Y., \& Huang, C. -J. (2016). Feasible management of southern corn leaf blight via induction of systemic resistance by Bacillus cereus $\mathrm{C} 1 \mathrm{~L}$ in combination with reduced use of dithiocarbamate fungicides. The Plant Pathology Journal, 32, 481-488.

Loladze, A. (2006). Development of a detached leaf assay for stripe resistance screening. M.Sc. Thesis, Washington State University, Washington, USA.

Maharijaya, A., Vosman, B., Steenhuis-Broers, G., Harpenas, A., Purwito, A., Visser, R. G. F., \& Voorrips, R. E. (2011). Screening of pepper accessions for resistance against two thrips species (Frankliniella occidentalis and Thrips parvispinus). Euphytica, 177, 401-410.

Michailides, T. J., Guo, L.-Y., \& Morgan, D. P. (1997). Factors affecting zygosporogenesis in Mucor piriformis and Gilbertella persicaria. Mycologia, 89, 603-609.

Michel, A. P., Mian, M. A. R., Davila-Olivas, N. H., \& Cañas, L. A. (2010). Detached leaf and whole plant assays for soybean aphid resistance: Differential responses among resistance sources and biotypes. Journal of Economic Entomology, 103, 949-957.

Moročko, I., Fatehi, J., \& Gerhardson, B. (2006). Gnomonia fragariae, a cause of strawberry root rot and petiole blight. European Journal of Plant Pathology, 114, 235-244.

Mubeen, S., Rafique, M., Munis, M. F. H., \& Chaudhary, H. J. (2017). Study of southern corn leaf blight (SCLB) on maize genotypes and its effect on yield. Journal of the Saudi Society of Agricultural Sciences, 16, 210-217.

Nelson, R. R., Ayers, J. E., Cole, H., \& Peterson, D. G. (1970). Studies and observations on the past occurrence and geographical distribution of isolates of race of Helminthosporium maydis. Plant Disease Report, 54, 1123-1126.

Patial, M., Kumar, J., \& Pal, D. (2017). Detached leaf assay for evaluating resistance to leaf rust Pst. 104-2 in wheat (Triticum aetivum L.). Indian Journal of Experimental Biology, 55, 789-794.

Rajkumar, M., Lee, W. H., \& Lee, K. J. (2005). Screening of bacterial antagonists for biological control of Phytophthora blight of pepper. Journal of Basic Microbiology, 45, 55-63.

Richmond A. E., \& Lang A. (1957). Effect of kinetin on protein content and survival of detached Xanthium leaves. Science, $125,650-651$ 
Sharma, H. C., Pampapathy, G., Dhillon, M. K., \& Ridsdill-Smith, J. T. (2005). Detached leaf assay to screen for host plant resistance to Helicoverpa armigera. Journal of Economic Entomology, 98, 568-576.

Shukla, R., Singh, P., Prakash, B., Anuradha, \& Dubey, N. K. (2012). Antifungal, aflatoxin inhibitory and free radicalscavenging activities of some medicinal plants extracts. Journal of Food Quality, 35, 182-189.

Siddiqui, M. W., Bhattacharjya, A., Chakraborty, I., \& Dhua, R. S. (2011). 6-Benzylaminopurine improves shelf life, organoleptic quality and health-promoting compounds of fresh-cut broccoli florets. Journal of Scientific and Industrial Research, 70, 461-465.

Singh, R., Mani, V. P., Khandelwal, R. S., Ram, L., \& Srivastava, R. P. (2014). Screening of maize genotypes against southern corn leaf blight. The Bioscan, 9, 859-862.

Smith, D. R., \& Hooker, A. L. (1973). Monogenic chlorotic-lesion resistance in corn to Helminthosporium maydis. Crop Science, 13, 330-331.

Srivastava, R., Singh, R., Mani, V. P., Khandelwal, R. S., \& Alam, M. (2017). Additional sources of resistance for southern corn leaf blight in Indian maize germplasm. Ekin Journal of Crop Breeding and Genetics, 3, 41-44.

Tatum, L. A. (1971). The southern corn leaf blight epidemic. Science, 171, 1113-1116.

Thompson, D. L., \& Bergquist, R. R. (1983). Inheritance of mature plant resistance to Helminthosporium maydis race $\mathrm{O}$ in maize. Crop Science, 24, 807-811.

Twizeyimana, M., Ojiambo, P. S., Ikotun, T., Paul, C., Hartman, G. L., \& Bandyopadhyay, R. (2007a). Comparison of field, greenhouse, and detached-leaf evaluations of soybean germplasm for resistance to Phakopsora pachyrhizi. Plant Disease, 91, 1161-1169.

Twizeyimana, M., Ojiambo, P. S., Tenkouano, A., Ikotun, T., \& Bandyopadhyay, R. (2007b). Rapid screening of Musa species for resistance to black leaf streak using in vitro plantlets in tubes and detached leaves. Plant Disease, 91, 308-314.
Ullstrup, A. J. (1972). The impacts of the southern corn leaf blight epidemics of 1970-1971. Annual Review of Phytopathology, 10, 37-50.

van Ittersum, M. K., van Bussel, L. G. J., Wolf, J., Grassini, P., van Wart, J., Guilpart, N., Claessens, L., de Groot, H., Wiebe, K., Mason-D’Croz, D., Yang, H., Boogaard, H., Van Oort, P. A. J., Van Loon, M. P., Saito, K., Adimo, O., Adjei-Nsiah, S., Agali, A., Bala, A., Chikowo, R., Kaizzi, K., Kouressy, M., Makoi, J. H. J. R., Ouattara, K., Tesfaye, K., \& Cassman, K. G. (2016). Can subSaharan Africa feed itself? Proceedings of the National Academy of Sciences of the United States of America, 113, 14964-14969.

Wang, M., Ma, J., Fan, L., Fu, K., Yu, C., Gao, J., Li, Y., \& Chen, J. (2015). Biological control of southern corn leaf blight by Trichoderma atroviride SG3403. Biocontrol Science and Technology, 25, 1133-1146.

Wei, J. K., Liu, K. M., Chen, J. P., Luo, P. C., \& Stadelmann, O. Y. L. (1988). Pathological and physiological identification of race $\mathrm{C}$ of Bipolaris maydis in China. Phytopathology, 78, $550-554$.

Weihmann, F., Eisermann, I., Becher, R., Krijger, J. J., Hubner, K., Deising, H. B., \& Wirsel, S. G. R. (2016). Correspondence between symptom development of Colletotrichum graminicola and fungal biomass, quantified by a newly developed $\mathrm{qPCR}$ assay, depends on the maize variety. $B M C$ Microbiology, 16, 94.

Zandjanakou-Tachin, M., Ojiambo, P. S., Vroh-Bi, I., Tenkouano, A., Gumedzoe, Y. M., \& Bandyopadhyay, R. (2013). Pathogenic variation of Mycosphaerella species infecting banana and plantain in Nigeria. Plant Pathology, 62, 298-308.

Zavaleta-Mancera, H. A., Lopez-Delgado, H., Loza-Tavera, H., Mora-Herrera, M., Trevilla-Garcia, C., Vargas-Suarez, M., \& Ougham, H. (2007). Cytokinin promotes catalase and ascorbate peroxidase activities and preserves the chloroplast integrity during dark-senescence. Journal of Plant Physiology, 164, 1572-1582. 